Pacific Journal of Mathematics

ALGEBRAS FOR WHICH EVERY INDECOMPOSABLE RIGHT
MODULE IS INVARIANT IN ITS INJECTIVE ENVELOPE 


\title{
ALGEBRAS FOR WHICH EVERY INDECOMPOSABLE RIGHT MODULE IS INVARIANT IN ITS INJECTIVE ENVELOPE
}

\author{
S. E. Dickson AND K. R. Fuller
}

The algebras of the title are characterized as those having Tachikawa's strong left cyclic representation type (SLCRT) with the further property that every quotient of a principal indecomposable left module has square free socle. Moreover it turns out that these are precisely the algebras for which every indecomposable right module is quasi-injective in the sense of Johnson and Wong, and that these algebras have finite module type.

Throughout, the letter $A$ denotes a finite dimensional algebra with radical $N$ over a field $K$ with more than two elements. All modules considered are unitary finitely generated $A$-modules. A completely reducible module $M$ is said to be square free if the homogeneous components of $M$ are simple. If $M$ is any module the socle of $M$ is the annihilator of $N$ in $M$ and the top of $M$ is the factor module $M / \operatorname{Rad} M$.

Johnson and Wong [3] have introduced the concept of a quasiinjective module, which is characterized as one that is carried into itself by all endomorphisms of its injective envelope. Tachikawa [5] has introduced algebras of strong left cyclic representation type (SLCRT). An algebra has SLCRT in case each of its indecomposable left modules is a quotient of a principal indecomposable (equivalently, has a simple top). He has given four ideal-theoretic conditions which, together, are necessary and sufficient for an algebra to have SLCRT. Our main result places the algebras of the title among those having SLCRT and distinguishes them by an additional condition on the left principal indecomposables. This condition is precisely the Curtis-Jans [1] condition that socles of indecomposable modules be square free, which yields algebras of finite module type (=those having a finite number of isomorphism classes of indecomposable modules) when the base field is algebraically closed. An algebra satisfying the conditions of the theorem is said to be of right invariant module type. We give an example to show that not all SLCRT algebras are of right invariant module type.

If $M$ is a quasi-injective module over any ring $R$ (equivalently, $M$ is stable under all $R$-endomorphisms of $E(M)$ [3, Th. 1.1]) then, as observed by $\mathrm{Wu}$ and Jans on page 442 of [6], $M$ decomposes whenever $E(M)$ does. Thus if $M$ is an indecomposable quasi-injective $R$ - 
module with an essential socle then $M$ is an $R$-End $(E(S))$ submodule of $E(S)$ where $S$ is the (necessarily) simple socle of $M$. In the case where $M$ is an $A$-module this observation and [6, Th. 3.1] are equivalent via the vector space dual. In the following lemma we show that for indecomposable $A$-modules a stronger result (and, of course, its dual) holds - namely, in order for an indecomposable $A$-module to be quasiinjective it is sufficient that it merely be invariant under the automorphisms of its injective envelope. The key to the proof is to show that an $A$-module satisfying this condition must have a simple socle.

Lemma. If an indecomposable A-module $M$ is invariant under the automorphisms of its injective envelope $E(M)$ then $M$ is quasiinjective.

Proof. Suppose $M$ does not have a simple socle. Let $M_{1} \oplus M_{2}$ be maximal with respect to being a decomposable submodule of $M$. Then each $M_{i}(i=1,2)$ is maximal with respect to $M_{1} \cap M_{2}=0$. It follows that $\left(M_{1} \oplus M_{2}\right) / M_{i}$ is essential in $M / M_{i}(i=1,2)$ and so the module $\left(M_{1} \oplus M_{2}\right) / M_{1} \oplus\left(M_{1} \oplus M_{2}\right) / M_{2}$ is essential in $M / M_{1} \oplus M / M_{2}$. But the diagonal copy of $M$, namely $M_{d}=\left\{\left(m+M_{1}, m+M_{2}\right) \mid m \in M\right\}$, is situated between the above two modules and hence is also essential in $M / M_{1} \oplus M / M_{2}$. Let $k \neq 1 \in K$ be a non-zero scalar, then the automorphism of the direct sum that takes the pair $\left(m+M_{1}, m+M_{2}\right)$ to $\left(k m+M_{1}, m+M_{1}\right)$ maps the copy $M_{d}$ into a different submodule of the direct sum, which is easily checked. It follows that $M$ is not invariant under the automorphisms of its injective envelope unless $M$ has simple socle. Thus if $M$ is invariant under the automorphisms of its injective envelope we see that $E(M)$ is indecomposable and has a completely primary endomorphism ring $R$. If $\alpha \in R$ then either $\alpha$ or $1-\alpha$ is an automorphism. In either case $\alpha(M) \subseteq M$ so $M$ is quasiinjective.

THEOREM. The following statements about the algebra $A$ are equivalent:

(a) Each indecomposable right A-module is carried into itself under the action of any automorphism of its injective envelope.

(b) Each indecomposable right A-module is carried into itself under the action of any endomorphism of its injective envelope (i.e., is quasi-injective).

(c) Each indecomposable left (right) A-module has simple top (socle) and square free socle (top).

Proof. The parenthetical version of (c) is equivalent to its non- 
parenthetical version by properties of the $K$-dual. We shall use the former in the proof.

(a) $\Leftrightarrow$ (b) This is a consequence of the lemma.

(b) $\Rightarrow$ (c) Since an indecomposable quasi-injective has simple socle, we see that each right principal indecomposable is uniserial whenever (b) is satisfied. Suppose this is the case but (c) does not hold. Then there is an indecomposable injective right module $E$ with submodules $x e A$ and $y e A(x, y \in E, e$ a primitive idempotent in $A)$ such that $x e A \nsubseteq y e A$ and $y e A \nsubseteq x e A$. But since $e A$ is uniserial, one of these is an epimorph of the other. This epimorphism, extended to an endomorphism of $E$, contradicts our assumption.

$(c) \Rightarrow(b)$ Assume (c) and suppose some indecomposable module $M$ is not mapped into itself by an endomorphism $\varphi$ of its injective envelope $E(S)$, where $S$ is the simple socle of $M$. Then there is a submodule $M^{\prime} \cong E(S)$ that is minimal with respect to $\varphi\left(M^{\prime}\right) \nsubseteq M^{\prime}$. Now $\varphi\left(M^{\prime} N\right) \subseteq M^{\prime} N$, so that the top of the indecomposable module $M^{\prime}+\varphi\left(M^{\prime}\right)$ is $\left(M^{\prime}+\varphi\left(M^{\prime}\right)\right) /\left(M^{\prime}+\varphi\left(M^{\prime}\right)\right) N=\left(M^{\prime}+\varphi\left(M^{\prime}\right)\right) / M^{\prime} N$ which is not square free. This contradiction completes the proof.

If $K$ is an algebraically closed field Curtis and Jans [1] have shown that $A$ is of finite module type if each indecomposable left $A$ module has a square free socle. However, even if $K$ is not algebraically closed, we have the

COROLlary. If the algebra $A$ is of right invariant module type then $A$ has finite module type.

Proof. If the submodule lattice of a principal indecomposable $A e$ is infinite then it is nondistributive and modular, and hence contains a projective root (see [2, p. 419]), which introduces a quotient of $\mathrm{Ae}$ with non-square free socle.

We do not know whether an arbitrary SLCRT algebra has finite module type. ${ }^{1}$

Remarks. (i) If $K$ is infinite, statement (c) of the theorem can be replaced by the demand that each indecomposable left module be a quotient of a principal indecomposable which has a finite submodule lattice.

(ii) One of Tachikawa's conditions states that an SLCRT algebra is right generalized uniserial. Thus any quasi-Frobenius algebra of right invariant module type is generalized uniserial.

${ }^{1}$ As this goes to press we note that A. V. Roiter's paper has appeared, Izv. Akad. Nauk S.S.S. R. Ser. Mat. 32 (1968), 1275-1282, in which the Brauer-Thrall conjecture is proved, answering this in the affirmative. 
(iii) Singh and Jain [4] have recently defined a pseudo-injective module as a module $M$ for which every monomorphism from a submodule of $M$ into $M$ can be extended to an endomorphism of $M$. They have shown that in certain special cases pseudo-injective modules are also quasi-injective. We note that by virtually copying the necessity part of the proof of [3, Th. 1.1] and the sufficiency part of [4, Th. 3.7] one can show that a module with a finitely generated essential socle is pseudo-injective if and only if it is invariant under the automorphisms of its injective envelope.

Examples. (i) Let $A$ be the algeba of matrices of the form

$$
\left[\begin{array}{lll}
x & 0 & 0 \\
u & x & 0 \\
v & w & y
\end{array}\right]
$$

with entries in any field $K$. This is an SLCRT algebra, as can be verified by checking Tachikawa's four conditions [5]. However the socle of the principal indecomposable $A e\left(e=e_{11}+e_{22}\right.$ with $e_{i j}$ the $i j$-th matrix unit) is not square free, so $A$ does not have right invariant module type.

(ii) The subalgebra $A^{\prime}$ of $A$ obtained by setting $w=0$ still satisfies Tachikawa's conditions and it is easily checked that every quotient of $A^{\prime} e$ has square free socle. The only other principal indecomposable is $A^{\prime} e_{33}$ which is already simple. Thus $A^{\prime}$ is an example of an algebra of right invariant module type that is not generalized uniserial.

\section{REFERENCES}

1. C. W. Curtis and J.P. Jans, On algebras with a finite number of indecomposable modules, Trans. Amer. Math. Soc. 114 (1965), 122-132.

2. J.P. Jans, On the indecomposable representations of algebras, Ann. of Math. (2) 66 (1957), 418-429.

3. R.E. Johnson and E.T. Wong, Quasi-injective modules and irreducible rings, J. London Math. Soc. 36 (1961), 260-268.

4. S. Singh and S.K. Jain, On pseudo-injective modules and self pseudo-injective rings, J. Math. Sci. 2 (1967), 23-31.

5. H. Tachikawa, On rings for which every indecomposable right module has a unique maximal submodule, Math. Z. 71 (1959), 200-222.

6. L. E. T. Wu and J.P. Jans, On quasi projectives, Illinois J. Math. 11 (1967) 439448.

Received October 11, 1968. The first author received partial support for this research under NSF Grant No. 8931.

The University of Southern California

IOWA STATE UNIVERSITY, AND

THE UNIVERSITY OF IOWA 


\title{
PACIFIC JOURNAL OF MATHEMATICS
}

\author{
EDITORS
}

\author{
H. ROYDEN \\ Stanford University \\ Stanford, California \\ RICHARD PIERCE \\ University of Washington \\ Seattle, Washington 98105
}

\author{
J. DUGUNDJI \\ Department of Mathematics \\ University of Southern California \\ Los Angeles, California 90007 \\ BASIL GORDON \\ University of California \\ Los Angeles, California 90024
}

\section{ASSOCIATE EDITORS}

E. F. BECKENBACH
B. H. NeumanN

F. WOLF
K. YoshidA

\section{SUPPORTING INSTITUTIONS}

\author{
UNIVERSITY OF BRITISH COLUMBIA \\ CALIFORNIA INSTITUTE OF TECHNOLOGY \\ UNIVERSITY OF CALIFORNIA \\ MONTANA STATE UNIVERSITY \\ UNIVERSITY OF NEVADA \\ NEW MEXICO STATE UNIVERSITY \\ OREGON STATE UNIVERSITY \\ UNIVERSITY OF OREGON \\ OSAKA UNIVERSITY \\ UNIVERSITY OF SOUTHERN CALIFORNIA
}

\author{
STANFORD UNIVERSITY \\ UNIVERSITY OF TOKYO \\ UNIVERSITY OF UTAH \\ WASHINGTON STATE UNIVERSITY \\ UNIVERSITY OF WASHINGTON

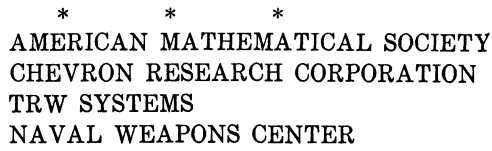

The Supporting Institutions listed above contribute to the cost of publication of this Journal, but they are not owners or publishers and have no responsibility for its content or policies.

Mathematical papers intended for publication in the Pacific Journal of Mathematics should be in typed form or offset-reproduced, double spaced with large margins. Underline Greek letters in red, German in green, and script in blue. The first paragraph or two must be capable of being used separately as a synopsis of the entire paper. It should not contain references to the bibliography. Manuscripts, in duplicate if possible, may be sent to any one of the four editors. Please classify according to the scheme of Math. Rev. 36, 1539-1546. All other communications to the editors should be addressed to the managing editor, Richard Arens, University of California, Los Angeles, California, 90024.

50 reprints are provided free for each article; additional copies may be obtained at cost in multiples of 50 .

The Pacific Journal of Mathematics is published monthly. Effective with Volume 16 the price per volume (3 numbers) is $\$ 8.00$; single issues, $\$ 3.00$. Special price for current issues to individual faculty members of supporting institutions and to individual members of the American Mathematical Society: $\$ 4.00$ per volume; single issues $\$ 1.50$. Back numbers are available.

Subscriptions, orders for back numbers, and changes of address should be sent to Pacific Journal of Mathematics, 103 Highland Boulevard, Berkeley, California, 94708.

PUBLISHED BY PACIFIC JOURNAL OF MATHEMATICS, A NON-PROFIT CORPORATION

Printed at Kokusai Bunken Insatsusha (International Academic Printing Co., Ltd.), 7-17, Fujimi 2-chome, Chiyoda-ku, Tokyo, Japan. 


\section{Pacific Journal of Mathematics}

\section{Vol. 31, No. $3 \quad$ BadMonth, 1969}

George E. Andrews, On a calculus of partition functions .................. 555

Silvio Aurora, A representation theorem for certain connected rings ............ 563

Lawrence Wasson Baggett, A note on groups with finite dual spaces ............. 569

Steven Barry Bank, On majorants for solutions of algebraic differential equations in regions of the complex plane ............................... 573

Klaus R. Bichteler, Locally compact topologies on a group and the corresponding continuous irreducible representations ......................... 583

Mario Borelli, Affine complements of divisors ....................... 595

Carlos Jorge Do Rego Borges, A study of absolute extensor spaces ............. 609

Bruce Langworthy Chalmers, Subspace kernels and minimum problems in Hilbert

spaces with kernel function ...................................... 619

John Dauns, Representation of L-groups and F-rings................. 629

Spencer Ernest Dickson and Kent Ralph Fuller, Algebras for which every

indecomposable right module is invariant in its injective envelope ...........

Robert Fraser and Sam Bernard Nadler, Jr., Sequences of contractive maps and fixed

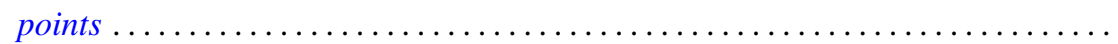

Judith Lee Gersting, A rate of growth criterion for universality of regressive

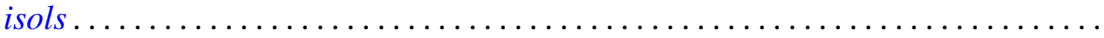

Robert Fred Gordon, Rings in which minimal left ideals are projective ............

Fred Gross, Entire functions of several variables with algebraic derivatives at certain algebraic points

W. Charles (Wilbur) Holland Jr. and Stephen H. McCleary, Wreath products of ordered permutation groups .........................

W. J. Kim, The Schwarzian derivative and multivalence .................. 717

Robert Hamor La Grange, Jr., On $(\mathrm{m}-\mathrm{n})$ products of Boolean algebras ......... 725

Charles D. Masiello, The average of a gauge ........................ 733

Stephen H. McCleary, The closed prime subgroups of certain ordered permutation

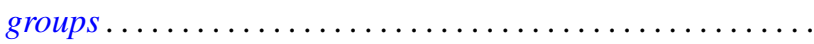

Richard Roy Miller, Gleason parts and Choquet boundary points in convolution measure algebras ...............................

Harold L. Peterson, Jr., On dyadic subspaces ........................ 773

Derek J. S. Robinson, Groups which are minimal with respect to normality being intransitive........................................... 777

Ralph Edwin Showalter, Partial differential equations of Sobolev-Galpern type . . . 787

David Slepian, The content of some extreme simplexes ................... 795

Joseph L. Taylor, Noncommutative convolution measure algebras ............. 809

B. S. Yadav, Contractions of functions and their Fourier series ............... 827

Lindsay Nathan Childs and Frank Rimi DeMeyer, Correction to automorphisms of separable algebras" ....................... 833

Moses Glasner and Richard Emanuel Katz, Correction to: "Function-theoretic degeneracy criteria for Riemannian manifolds".............

Satish Shirali, Correction to: "On the Jordan structure of complex Banach

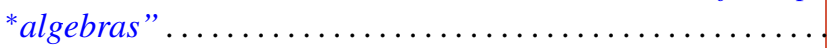

